\title{
What Do Secondary Preservice Mathematics Teachers Need to Know? Content Courses Connecting Secondary and Tertiary Mathematics
}

\author{
Eileen Murray and Jon R. Star
}

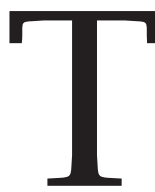
he recently released report The Mathematical Education of Teachers II (MET-II) [Conference Board of the Mathematical Sciences (CBMS), 2012] notes that, while most secondary mathematics teachers major in mathematics, many of the courses taken focus on mathematics needed for graduate study or careers in business. Prospective mathematics teachers could be better served by courses that "provide opportunities for future teachers to learn the mathematics they need to know to be wellprepared beginning teachers who will continue to learn new mathematical content and deepen their understanding of familiar topics" [CBMS, 2012, p. 5]. At present we appear to be in an exciting period of innovation and experimentation in the development of such courses, as mathematicians with interest in secondary education have created a wide array of new courses designed specifically for mathematics majors studying to become teachers.

Teacher education programs include a variety of courses designed to improve teachers' knowl-

Eileen Murray is a postdoctoral research fellow at Harvard University in the Graduate School of Education. Her email address is ei 1een_murray@harvard.edu .

Jon R. Star is associate professor in human development and education in the Graduate School of Education at Harvard University. His email address is Jon_Star@ Harvard. edu.

DOI: http://dx.doi.org/10.1090/noti1048 edge. These courses fall largely into two categories: mathematics courses offered by mathematics departments and teaching methods courses offered by education departments. Many teaching methods courses have begun to incorporate content knowledge, especially as it relates to the mathematics prospective teachers will teach and the specialized mathematical knowledge needed for the specific tasks of teaching [Ball, Thames, and Phelps, 2008]. Yet there does not appear to have been substantial change in the types of mathematics content courses that prospective teachers (as mathematics majors) take, with one exception. There are a growing number of courses offered by mathematics departments where prospective teachers learn new mathematics while simultaneously building connections between tertiary and secondary mathematics. These connections courses are presumed to help prospective secondary mathematics teachers (PSMT) situate and motivate the mathematics that they will teach.

The impetus for the increasing number of connections courses has come about for at least two reasons. First, research over the past twenty-plus years has articulated the need for such knowledge, expanded our thinking about what mathematics teachers need to know, and pushed us to think about how this knowledge develops. Second, we see an increasing number of productive and sustained collaborations between mathematicians and mathematics educators, such that many in the 
mathematics community are now engaged in efforts to improve K-12 mathematics education.

To better understand the landscape of connections courses, we conducted an informal survey of institutions to uncover some of the innovative courses that are currently offered to PSMT. We looked at department websites, spoke with colleagues in mathematics and mathematics education, collected syllabi, and interviewed course instructors. We concluded that the landscape of connections courses appears to be composed of two distinct types of courses: (a) secondary mathematics from an advanced standpoint and (b) tertiary mathematics with connections.

In secondary mathematics from an advanced standpoint courses, secondary mathematics topics are covered at a level of depth and rigor suitable for undergraduate mathematics students, but the connections to the mathematics content PSMT will be teaching are explicitly investigated. Such focus allows teachers to see the importance of the mathematics they are required to take as undergraduates and contemplate pedagogical strategies that might support students' thinking in ways that can make advanced mathematics more accessible.

For example, mathematicians and mathematics educators at Michigan State University (MSU) have developed a capstone course for mathematics majors planning on becoming secondary teachers. The course aims to deepen PSMT understanding of secondary mathematics by focusing specifically on analysis and algebra, as well as to help PSMT describe the connections among secondary topics and connections between secondary and tertiary mathematics. Since the course is an upper-level mathematics course, it is not simply a high school mathematics class, but one that (according to the course syllabus) provides students "insight and understanding of high school mathematics from the viewpoint of junior/senior-level college mathematics." Objectives include analyses of alternative approaches to mathematical ideas, extensions and generalizations of familiar theorems, and discussions of relations between topics studied in this course and contemporary high school curricula.

To achieve these objectives, the MSU course uses two textbooks: Mathematics for High School Teachers-An Advanced Perspective [Usiskin et al., 2002] and Field Theory and Its Classical Problems [Hadlock, 1979]. The first textbook approaches secondary topics using tertiary mathematics, such as by considering algebraic structures and solving equations by considering seemingly simple questions such as, When do the equations $\mathrm{a}+x=$ $\mathrm{b}$ and $\mathrm{a} x=\mathrm{b}$ have solutions? When are those solutions unique? When are there no solutions? These questions extend high school algebra to abstract algebra through the generalization of the operations of addition and subtraction to any binary operation. Such explorations can deepen teachers' knowledge about solving equations and the nature of solutions.

The second textbook delves into interesting problems in Galois theory but requires nothing more than knowledge of calculus and linear algebra. Hadlock illustrates connections between tertiary and secondary mathematics by discussing classical Greek problems that are presented in high school but never proved (e.g., trisecting an angle) and by devoting significant attention to polynomials, a secondary topic, using fields and field extensions. When approaching classical problems, the course prompts MSU students to create a bridge between the mathematics they will teach and solutions that may require more complex mathematics.

The second type of connections course, tertiary mathematics with connections, aims to provide PSMT with the knowledge necessary to teach mathematics effectively by beginning with tertiary content and subsequently focusing on the importance of these topics within secondary mathematics. These courses generally focus on one content area, such as algebra, real analysis, or geometry, which appears to be most relevant to high school teaching. The courses largely use advanced textbooks, and connections are drawn from class discussion or supplementary materials usually written by the instructor.

For example, the University of Illinois-Chicago offers a tertiary-mathematics-with-connections course in real analysis for PSMT, Mathematical Analysis for Teachers. The goals are to provide a rigorous first course in real analysis and insight into connections between what PSMT learn in college and the secondary mathematics they will be teaching. Students embark on a rigorous, axiomatic development of the real number system where they are required to prove most theorems. Students then prove the major theorems of calculus and find and explain examples and counterexamples to definitions and theorems encountered. Connections naturally arise throughout the course through common errors in teaching and doing secondary mathematics that are unavoidable because of the nature of mathematics. For example, students have the opportunity to discuss solutions to quadratic (and higher polynomial) equations when they work to prove that there are no zero divisors for the real numbers. Many PSMT may be comfortable saying that if $(x-1)(x-3)=0$, then $x$ $=1$ and $x=3$ are the solutions. However, without the above theorem they cannot explain why these are the only two solutions. Examples such as this one aim to provide PSMT with the opportunity to see how concepts and methods of proof in real analysis are directly applicable to the mathematics they will be teaching.

Secondary mathematics teachers need deep knowledge of mathematics to be effective. Recent policy documents, including the MET-II report, 
make clear that secondary mathematics teachers not only need high-quality content courses but also a set of different kinds of learning experiences that help make connections between tertiary and secondary mathematics.

We have focused on two types of courses: secondary mathematics from an advanced standpoint and tertiary mathematics with connections. While we feel confident in the legitimacy of these two categories of connections courses, we acknowledge that there may be courses and categories we were unable to detect in our inquiry. However, our goal was to try to capture the range of what might exist at present, showcase some of the courses that are working to build specific content knowledge for PSMT, and stimulate dialogue. We hope that our work can become a springboard for more systematic analyses of the spectrum of content courses now being offered and developed across the U.S. We believe that these courses can help prepare our future mathematics teachers by building a strong foundation of mathematical content knowledge.

\section{References}

1. D. L. Ball, M. H. Thames, and G. Phelps, Content knowledge for teaching: What makes it special? Journal of Teacher Education 59 (5) (2008), 389-407.

2. Conference Board of the Mathematical Sciences (CBMS), The Mathematical Education of Teachers II (MET-II), American Mathematical Society, Providence, Rhode Island, 2012.

3. C. R. HADLOCK, Field Theory and Its Classical Problems, Mathematical Association of America, Washington, DC, 1979.

4. Z. Usiskin, A. L. Peressini, E. MARchisotto, and D. STANLEY, Mathematics for High School TeachersAn Advanced Perspective, Pearson, 2002.

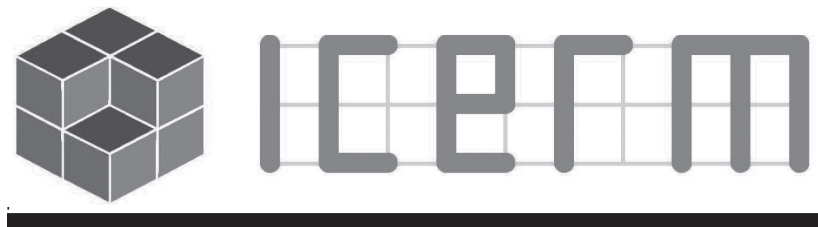

Institute for Computational and Experimental Research in Mathematics

SEMESTER PROGRAM: SPRING 2014

\section{Network Science and Graph Algorithms February 3, 2014 - May 9, 2014}

\section{Organizing Committee:}

Andrea Bertozzi, University of California, Los Angeles Jonathan Kelner, Massachusetts Institute of Technology Philip Klein, Brown University

Claire Mathieu, CNRS/Ecole Normale Supérieure/Brown University

David Shmoys, Cornell University

Eli Upfal, Brown University

\section{Description:}

The study of computational problems on graphs has long been a central area of research in computer science. However, recent years have seen qualitative changes in both the problems to be solved and the tools available to do so. Application areas such as computational biology, the web, social networks, and machine learning give rise to large graphs and complex statistical questions that demand new algorithmic ideas and computational models. A wide variety of techniques are emerging for addressing these challenges: from semidefinite programming and combinatorial preconditioners.

\section{Workshops:}

- Semidefinite Programming and Graph Algorithms (February 10-14, 2014)

- Stochastic Graph Models (March 17-21, 2014)

- Electrical Flows, Graph Laplacians, and Algorithms: Spectral Graph Theory and Beyond (April 7-11, 2014)

- Eigenvectors in Graph Theory and Related Problems in Numerical Linear Algebra (May 5-9, 2014)

Research Clusters:

- Geometric Analysis Methods for Graph Algorithms (February 3-28, 2014)

- Graphs with Incomplete Information (February 17-March 14, 2014)

- Towards Efficient Algorithms Exploiting Graph Structure (April 24-May 2, 2014)

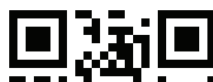 \\ 14. Program details: P1j.1 http://icerm.brown.edu a}

About ICERM: The Institute for Computational and Experimental Research in Mathematics is a National Science Foundation Mathematics Institute at Brown University in Providence, Rhode Island. Its mission is to broaden the relationship between mathematics and computation.
121 S. Main Street, 11th Floor Providence, RI 02903 401-863-5030 info@icerm.brown.edu

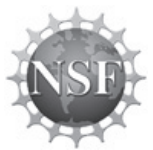

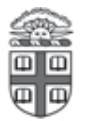

